\title{
Systemic administration of a TLR7 agonist attenuates regulatory $T$ cells by dendritic cell modification and overcomes resistance to PD-L1 blockade therapy
}

\author{
Naoto Nishii, ${ }^{1,2}$, Hidetake Tachinami ${ }^{1}$, Yuta Kondo ${ }^{1}$, Yulong Xia ${ }^{1}$, Yoshihisa \\ Kashima $^{1,2}$, Tatsukuni Ohno ${ }^{1}$, Shigenori Nagai ${ }^{1}$, Lixin Li $^{3}$, Walter Lau ${ }^{3}$, Hiroyuki \\ Harada $^{2}$ and Miyuki Azuma ${ }^{1}$ \\ ${ }^{1}$ Department of Molecular Immunology, Graduate School of Medical and Dental Sciences, Tokyo Medical and Dental University \\ (TMDU), Tokyo, Japan \\ ${ }^{2}$ Department of Oral and Maxillofacial Surgery, Graduate School of Medical and Dental Sciences, Tokyo Medical and Dental \\ University (TMDU), Tokyo, Japan \\ ${ }^{3}$ Birdie Biopharmaceuticals Inc., Iselin, NJ, USA \\ Correspondence to: Miyuki Azuma, email: miyuki.mim@tmd.ac.jp
}

Keywords: TLR7 agonist; resiquimod; immune checkpoint blockade; companion drug; regulatory T cells

Received: November 11, $2017 \quad$ Accepted: January 19, $2018 \quad$ Published: January 27, 2018

Copyright: Nishii et al. This is an open-access article distributed under the terms of the Creative Commons Attribution License 3.0 (CC BY 3.0), which permits unrestricted use, distribution, and reproduction in any medium, provided the original author and source are credited.

\section{ABSTRACT}

Research on immune checkpoint blockade therapy has made great progress in cancer immunotherapy, but the number of patients who benefit from this therapy remains limited. In this study, we examined the effects of monotherapy with systemic low-dose resiquimod, a synthesized TLR7 agonist, and examined its combined effects with PD-L1 blockade in two PD-L1 blockade-resistant tumor models (SCCVII and Colon 26). Resiquimod monotherapy in SCCVII tumors, representing impaired $\mathrm{CDB}^{+} \mathbf{T}$ cell function and accelerated regulatory $T$ cells (Tregs) within the tumors, efficiently reduced tumor growth with more recruitment of $\mathrm{CD8}^{+} \mathrm{T}$ cells and a reduction of Treg. The results of resiquimod monotherapy in Colon 26, representing impaired Treg recruitment, were inferior to that in SCCVII. Combined resiquimod treatment with PD-L1 blockade exerted clear additional effects, as it was associated with reduced tumor size, attenuation of Tregs, and an increased ratio of $\mathrm{CD8}^{+} \mathrm{T}$ cells/Tregs in both tumors. Systemic administration of low-dose resiquimod induced a transient and rapid activation of plasmacytoid and conventional dendritic cells, resulting in enhanced priming of $\mathrm{T}$ cells in regional lymph nodes. Experiments with more limited doses of resiquimod that did not yield beneficial effects after single treatment, showed additional effects to PD-L1 blockade and comparable antitumor effects when the frequency of anti-PD-L1 therapy was decreased. Our results suggest that systemic administration of low-dose resiquimod is useful as a companion drug to PD-1/PD-L1 blockade therapy.

\section{INTRODUCTION}

The blockade of immune checkpoint molecules, such as CTLA-4 and PD-1, efficiently enhances antitumor immune responses by eliminating the immunoregulatory function of effector $\mathrm{T}$ cells, regulatory $\mathrm{T}$ cells (Tregs), myeloid-derived suppressor cells (MDSCs), and tumor- associated macrophages (TAMs) [1-4]. However, individual patients who receive the benefits of immune checkpoint blockade differ greatly by clinical grade and tumor tissue type. Head and neck cancers (HNCs) do not frequently express the tumor-specific mutated antigens (called "neoantigens") that elicit T-cell immunoreactivity and influence sensitivity to immune checkpoint blockade 
therapy $[5,6]$, and their tumor microenvironment (TME) contains abundant regulatory cells, such as Tregs and MDSCs [7-9]. We recently demonstrated that blockade of either CTLA-4 or PD-1 efficiently inhibited the tumor growth of a murine squamous cell carcinoma (SCC) cell line (SCCVII) in syngeneic mice; however, we failed to eradicate the tumors [10]. The ratio of effector $\mathrm{CD}^{+}$ $\mathrm{T}$ cells/Tregs (CD8/Treg) closely associated with the prognosis and outcome of immunotherapy $[10,11]$.

Toll-like receptors (TLRs) recognize a wide panel of exogenous and endogenous ligands, and the binding of natural and synthetic TLR ligands to TLRs induces multiple cytokine production, resulting in enhanced innate and adaptive immunity [12-14]. Small compounds that are designed to bind TLRs are potential drugs for vaccines and adjuvants in infectious disease and cancer. TLR7 and TLR8, which are expressed on endosomes, have structural similarity and recognize microbial single-stranded RNA (ssRNA). Imiquimod (R837) and resiquimod (R848), which are imidazoquinoline compounds of synthesized ssRNAs, bind TLR7 alone and both TLR7 and TLR8, respectively $[15,16]$. Resiquimod does not exert mouse TLR8mediated activation. TLR7/8-mediated signaling induces the production of NF-kB-mediated proinflammatory cytokines and chemokines, and type I interferon (IFN) by activating antigen-presenting cells (APCs), resulting in the augmentation of effector T cells $[12,17,18]$. Nevertheless, imidazoquinolines have been applied in the clinical setting only in the form of a topical treatment or a locally administrated drug for the treatment of non-melanoma skin cancers and viral skin lesions to avoid TLR tolerance and adverse proinflammatory and proapoptotic effects [19-22].

Recently, systemic or intratumoral administration of TLR7 agonists, such as resiquimod and its related conjugate, has shown to induce efficient tumor regression by inhibiting TAM- or MDSC-mediated immune suppression in murine tumor models [23, 24]. In PD-1 blockade therapy-resistant and immunosuppressive tumors, such as HNC, combined treatment with a TLR7 agonist and PD-1 blockade might be an effective cancer immunotherapy. In this study, we examined the effects of monotherapy of systemic lowdose resiquimod and combined therapy with anti-PD-L1 treatment in two PD-L1 blockade-resistant tumor models.

\section{RESULTS}

\section{The TME of SCCVII presents a more immunosuppressed status}

Colon 26 is a carcinogen-induced undifferentiated colon carcinoma cell line that originated from BALB/c mice, and SCCVII is a spontaneously arising SCC cell line derived from $\mathrm{C} 3 \mathrm{H} / \mathrm{HeN}(\mathrm{C} 3 \mathrm{H})$ mice $[25,26]$. PD1:PD-L1 blockade therapy in these tumor models did not completely eradicate the tumors in syngeneic mice ([10] and data discussed below). Although both cultured tumor cell lines showed no or marginal PD-L1 expression, IFN- $\gamma$ treatment for $72 \mathrm{hr}$ efficiently increased its expression (Figure 1A). Furthermore, immunohistochemistry showed that subcutaneously inoculated tissue tumor cells expressed PD-L1; however, its expression levels varied by lesions (Figure 1B). PD-L1 expression in both tumors is inducible in vitro and in vivo. To investigate the differences between the host immune responses in both tumors, we examined the phenotypes and activation status of tumor infiltrating lymphocytes (TILs). Compared with Colon 26, CD45 ${ }^{+}$pan-leukocytes in the SCCVII-TIL fractions contained a lower percentage of $\mathrm{CD}^{+} \mathrm{T}$ and a greater percentage of CD11 $\mathrm{b}^{+}$myeloid cells (Figure 1C). These $\mathrm{CD}_{11} \mathrm{~b}^{+}$cells presented with high forward scatter, and antigenic profiles that were Gr-1-negative and F4/80positive, indicating a phenotype consistent with TAMs (Supplementary Figure 4A). $\mathrm{CD}^{+} \mathrm{T}$ cells in SCCVIITILs had a significantly lower percentage of $\mathrm{CD} 8^{+} \mathrm{T}$ and a greater percentage of $\mathrm{CD} 4^{+} \mathrm{Foxp}^{+}$Tregs. Furthermore, a significantly lower proportion of $\mathrm{CD} 8^{+} \mathrm{T}$ cells expressed IFN- $\gamma$. These results show that the TME in SCCVII had impaired effector cytotoxic T lymphocytes (CTLs) and a high recruitment of immunoregulatory TAMs and Tregs.

\section{Systemic low-dose resiquimod administration induces a transient upregulation of serum IFN- $\alpha$}

To avoid unwanted proinflammatory cytokine production by systemic resiquimod injection, we first used a low dose $(1.7 \mu \mathrm{g} / \mathrm{mouse})$ of resiquimod compared with the dose of other imidazoquinoline-like molecules injected in mice $[23,27]$. Serum proinflammatory cytokines in intact and SCCVII tumor-inoculated $\mathrm{C} 3 \mathrm{H}$ mice were measured. At $3 \mathrm{hr}$ after resiquimod injection, serum IFN- $\alpha$ increased transiently, but it returned to an undetectable level at $12 \mathrm{hr}$ (Table 1). Similar to IFN- $\alpha$, IL-6 also increased at $3 \mathrm{hr}$, albeit only slightly, and was undetectable at $12 \mathrm{hr}$. This dose of resiquimod did not increase IL-1 $\beta$ and TNF- $\alpha$. Tumor inoculation slightly upregulated serum IFN- $\alpha$ and IL- 6 production, but these diminished quickly. These results indicate that systemic injection of a low-dose of resiquimod did not induce the production of multiple proinflammatory cytokines, but induced temporal activation of plasmacytoid DCs (pDCs), that expressed high levels of TLR7 [28], which may contribute to the selective and transient upregulation of IFN- $\alpha$.

\section{Systemic low-dose resiquimod administration efficiently reduces tumor growth and enhances the efficacy of PD-L1 blockade therapy}

We examined the effects of monotherapy with either PD-L1 blockade or resiquimod, and of combined therapy in two tumor models (Colon 26 and SCCVII). The addition of resiquimod to each tumor cell culture did not clearly affect tumor growth, indicating that both 
tumor cells did not directly respond to resiquimod. In preliminary experiments, treatment started at day 0 (early treatment) and day 7 (delayed treatment). Although the delayed treatment in SCCVII tumors showed effects comparable to those of the early treatment, the delayed treatment worsened the effects in Colon 26. Thus, thereafter, we used only early treatment for Colon 26 and delayed treatment for SCCVII. Treatment with antiPD-L1 monotherapy did not clearly affect the tumor growth of Colon 26 (Figure 2A). A similar treatment in SCCVII slightly decreased the tumor volume, and the growth curves of individual SCCVII tumors reflected three response groups (resistant, moderate, and sensitive) (Figure 2B). Resiquimod monotherapy markedly inhibited tumor growth in both tumor models, and its inhibitory effect was much more obvious in SCCVII. Regarding Colon 26 tumors, an assessment of mean tumor volume did not show combined effects, but individual growth curves showed bilateral groups of tumor size (large and small) (Figure 2A). It should be noted that the images of the resected tumors in the combined therapy showed clear and widespread necrotic lesions with a dark red color, especially in the large tumor masses (Figure 2A). This suggests additional antitumor effects in Colon 26 by the combined therapy. In SCCVII tumors, the combined therapy gradually decreased tumor growth from day 13 to the final observation day (day 19), and the mean tumor volume on the final day was significantly reduced (Figure 2B). The tumor size in over half the mice remained unchanged in the last 4 days, and five mice showed only scar-like lesions, suggesting almost complete eradication of the tumors. Our results demonstrate that systemic low-dose resiquimod administration efficiently reduced tumor growth, and combined treatment with PD-L1 blockade exerted additional effects in two tumor models.

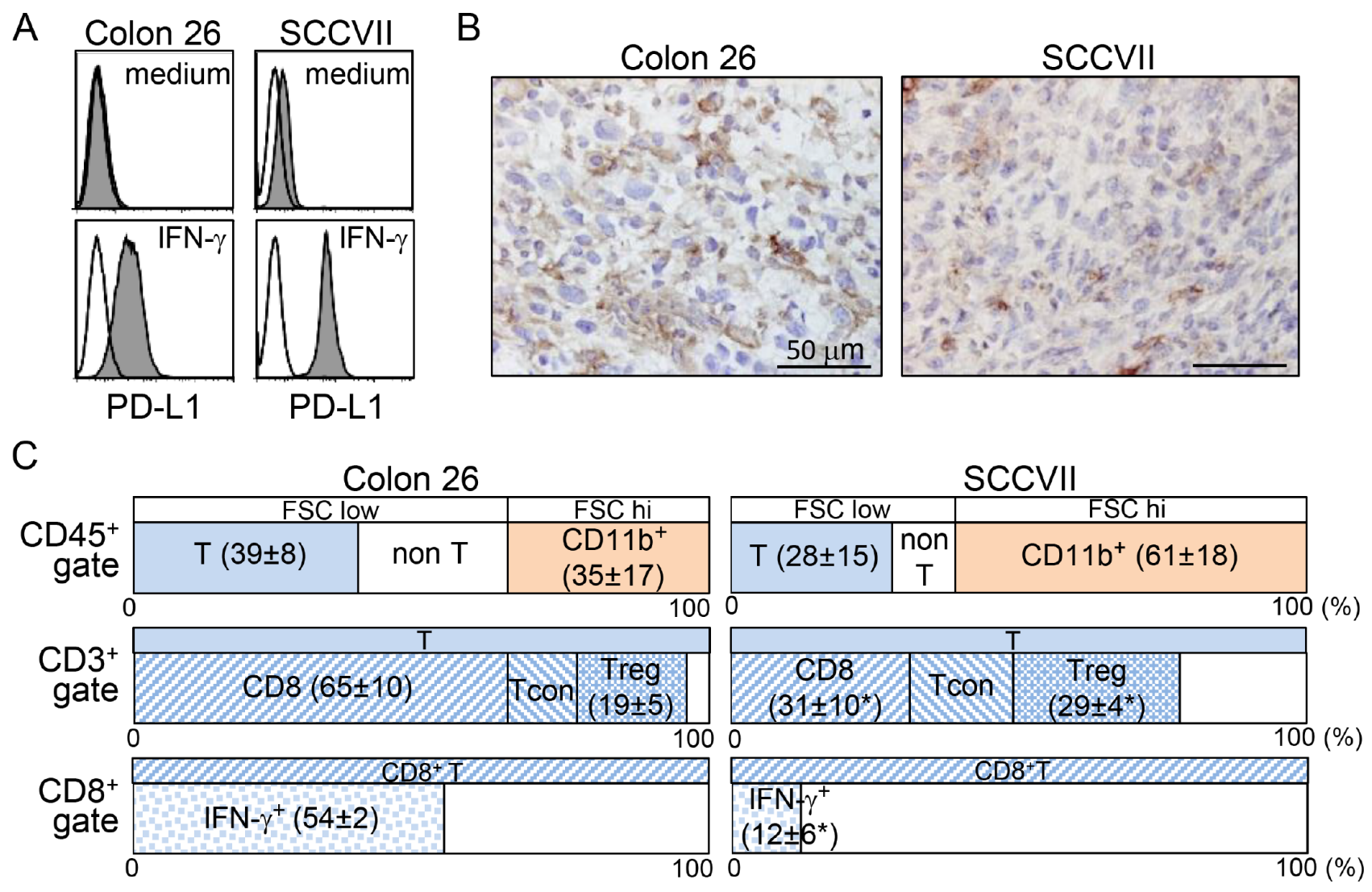

Figure 1: Colon 26 and SCCVII tumors exhibit distinct host immune responses in the TME. (A) Colon 26 and SCCVII tumor cells lines cultured in the presence or absence of IFN- $\gamma$ for $72 \mathrm{hr}$ were stained with PE-conjugated control rat IgG2a or anti-PD-L1 (MIH5) $\mathrm{mAb}$. Expression levels of PD-L1 are displayed as shaded histograms with the control staining displayed as open histograms. (B) Tumor tissue sections at 20 days after tumor inoculation were stained with anti-PD-L1 (MIH6) mAb. Scale bars $=50 \mu$ M. (C) TIL fractions from Colon 26 and SCCVII tumor masses at day 19 were stained and analyzed by flow cytometry. To avoid the loss of adherent cells, the percentage of CD45 cells was obtained from cells without in vitro stimulation culture. An electronic gate was placed on $\mathrm{CD}^{4} 5^{+} \mathrm{FSC}^{\text {low-high }}$ lymphocytes, and then the proportions of $\mathrm{FSC}^{\text {low }} \mathrm{CD}^{+} \mathrm{CD} 11 \mathrm{~b}^{-}(\mathrm{T})$ and $\mathrm{FSC}^{\text {med-high }} \mathrm{CD} 3{ }^{-} \mathrm{CD} 11 \mathrm{~b}^{+}$myeloid cells within $\mathrm{CD}^{2} 5^{+}$pan-lymphocytes were then analyzed. For T-cell analysis, electronic gates were placed on $\mathrm{FSC}^{\text {low }} \mathrm{CD}_{4} 5^{+} \mathrm{CD}^{+}\left(\mathrm{CD}^{+} \mathrm{T}\right)$ or $\mathrm{FSC}^{\text {low }} \mathrm{CD}^{+} \mathrm{CD}^{+}\left(\mathrm{CD} 8^{+} \mathrm{T}\right)$ cells, and then the proportions of $\mathrm{CD}^{+} \mathrm{CD}^{-}\left(\mathrm{CD} 8^{+} \mathrm{T}\right), \mathrm{CD} 8{ }^{-C D} 4^{+}{ }^{+}$oxp $33^{-}$(conventional T, Tcon), CD8-CD4 ${ }^{+}$Foxp3 ${ }^{+}$(Treg) within T cells, and IFN- $\gamma^{+}$cells within CD8 ${ }^{+} \mathrm{T}$ cells were analyzed. The values show the mean \pm SD from each group of five mice. ${ }^{*}$ Statistically different $(p<0.05)$. 
Table 1: Serum cytokines after resiquimod injection

\begin{tabular}{|c|c|c|c|c|c|c|c|c|c|}
\hline \multirow{2}{*}{$\begin{array}{l}\text { cytokines } \\
\text { tumor inoculation" }^{*}\end{array}$} & & \multicolumn{2}{|c|}{ IFN- $\alpha(\mathrm{pg} / \mathrm{ml})$} & \multicolumn{2}{|c|}{ IL-1及 (pg/ml) } & \multicolumn{2}{|c|}{ IL-6 (pg/ml) } & \multicolumn{2}{|c|}{ TNF- $\alpha(\mathrm{pg} / \mathrm{ml})$} \\
\hline & & - & + & + & - & - & + & - & + \\
\hline \multirow{4}{*}{ hr after resiquimod injection } & 0 & $<62$ & $<62$ & $<62$ & $<62$ & $<62$ & $<62$ & $<62$ & $<62$ \\
\hline & 3 & $2216 \pm 697$ & $3271 \pm 2615$ & $<62$ & $<62$ & $138 \pm 45$ & $157 \pm 74$ & $<62$ & $<62$ \\
\hline & 12 & $<62$ & $<62$ & $<62$ & $<62$ & $<62$ & $<62$ & $<62$ & $<62$ \\
\hline & 24 & $<62$ & $106 \pm 92$ & $<62$ & $<62$ & $<62$ & $<62$ & $<62$ & $<62$ \\
\hline
\end{tabular}

"40 Gy-irradiated-SCCVII cells.

A Colon 26
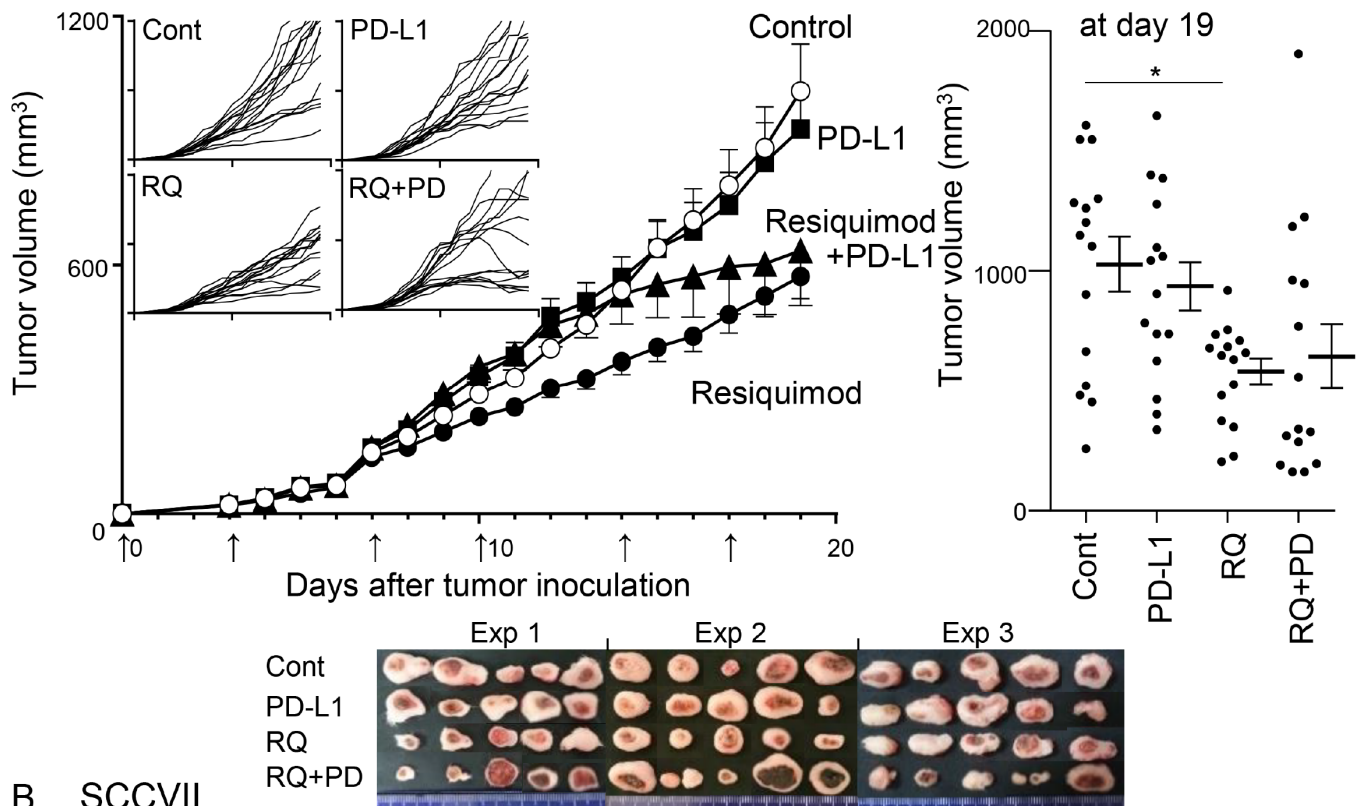

B SCCVII
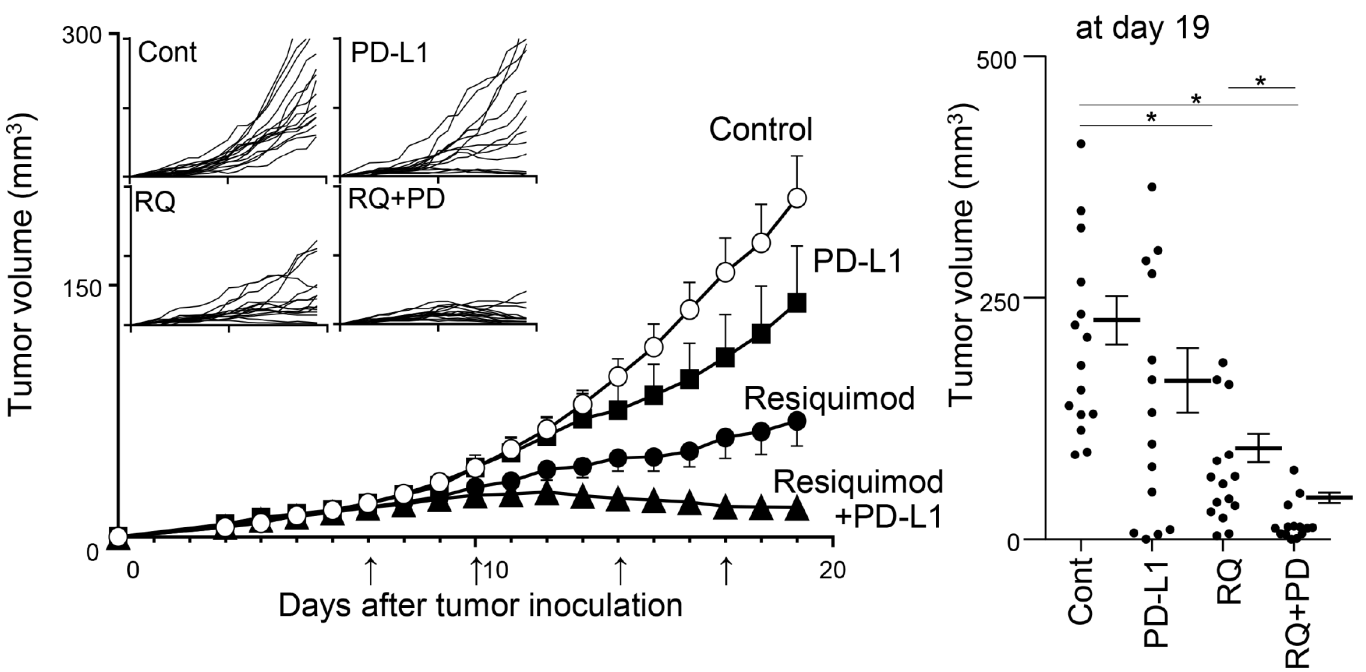

Figure 2: Effects of treatments with resiquimod and/or PD-L1 blockade in Colon 26 and SCCVII tumor models. Colon 26 (A) and SCCVII (B) tumor cells were inoculated into BALB/c and C3H mice, and treatments were started on day 0 and day 7 , respectively. Control reagents (PBS or rat IgG), resiquimod (RQ), anti-PD-L1 mAb (PD-L1) and both (RQ+PD) were injected i.p. twice a week until day 17. The arrows indicate the time of treatment. Tumor volume was measured every day. The values are the mean $\pm \mathrm{SEM}$ from three independent experiments with each group of five mice. * Statistically different $(p<0.05)$. The four smaller panels on the left show the individual growth curves. The final tumor volumes on day 19 are shown in the right panels. Digital photo images of resected Colon 26 tumor masses on day 19 are shown in the lower panel of A. 


\section{Resiquimod combined with PD-L1 blockade modulates recruitment of $\mathrm{CD8}^{+} \mathrm{T}$ cells and Tregs in the TME}

The proportions of three T-cell subsets; $\mathrm{CD} 8^{+} \mathrm{T}$, Foxp3 ${ }^{-} \mathrm{CD} 4^{+}$conventional $\mathrm{CD} 4{ }^{+} \mathrm{T}$ (Tcon), and Foxp ${ }^{+} \mathrm{CD} 4{ }^{+}$ Treg, within $\mathrm{CD}^{2} 5^{+}$TILs and IFN- $\gamma$ expression within $\mathrm{CD} 8^{+}$and $\mathrm{CD} 4^{+}$Tcon cells were determined on the final day. In Colon 26 tumors, no T-cell subset was clearly affected by either monotherapy, but the combined treatment significantly decreased the Treg proportion compared with the control and PD-L1 blockade groups (Figure 3A). This resulted in an increase in the CD8/Treg ratio. IFN- $\gamma$ expression levels in both $\mathrm{CD}^{+} \mathrm{T}$ and Tcon were increased by the combined treatment, although the difference was not statistically significant. Interestingly, resiquimod monotherapy in SCCVII efficiently increased the proportion of $\mathrm{CD} 8^{+} \mathrm{T}$ cells and decreased the proportion of Tregs, resulting in a marked elevation of the CD8/Treg ratio in some mice (Figure 3B). PD-L1 blockade alone also significantly increased the percentage of $\mathrm{CD} 8^{+} \mathrm{T}$ cells and the $\mathrm{CD}$ 8/Treg ratio. An additional resiquimod treatment combined with PD-L1 blockade further decreased the proportion of Tregs and resulted in an improved CD8/Treg ratio in most mice. Consistent with the findings in Colon 26 tumors, the expression levels of IFN- $\gamma$ in both $\mathrm{CD}^{+} \mathrm{T}$ and Tcon were not clearly affected. These results indicate that systemic administration of low-dose resiquimod in the Treg-dominant SCCVII markedly decreased the proportion of Tregs and reciprocally promoted CTL recruitment in the TME. Unlike the findings for SCCVII, similar treatment in a relatively CTL-rich Colon 26 tumor model reduced Treg recruitment without affecting CTLs. Taken together, our results indicate that systemic low-dose resiquimod administration in addition to PD-L1 blockade is especially effective for elevating the $\mathrm{CD} 8$ /Treg ratio in the TME.

\section{Resiquimod quickly enhances activation of two types of DCs}

To understand the mechanisms by which systemic low-dose resiquimod administration enhanced antitumor

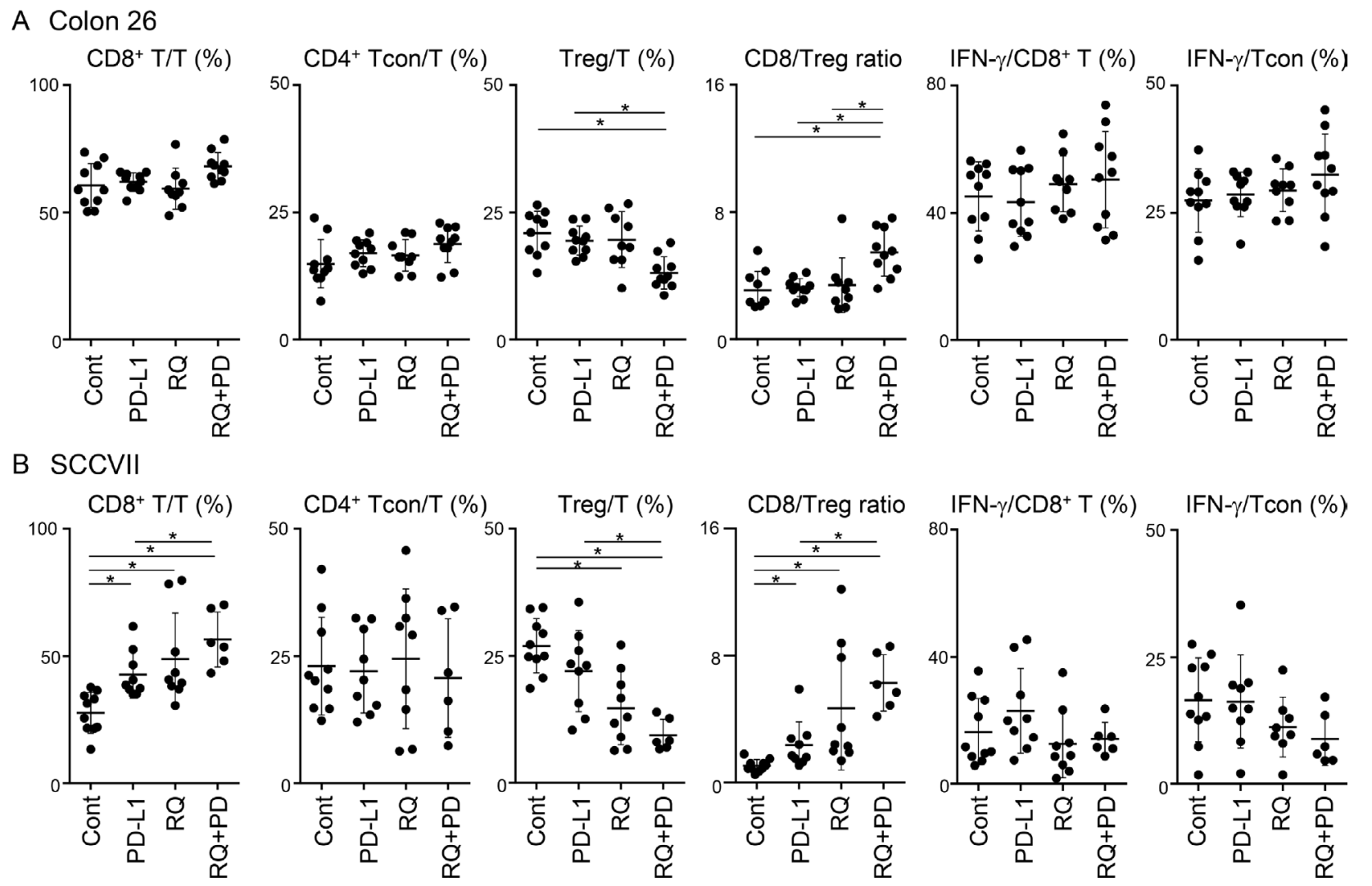

Figure 3: Changes of T-cell subsets and IFN- $\gamma$ expression in TILs by treatments. Tumor masses from Colon 26- (A) and SCCVII- (B) inoculated mice were collected and TILs were obtained. Cells were stimulated with PMA, ionomycin, and brefeldin A for $6 \mathrm{hr}$, and then cell surface and intracellular staining was performed. Cells were stained with FITC-anti-CD45, APC-eFluor780-anti-CD3, PE-Cy7-anti-CD4, PerCP-Cy5.5-anti-CD8, APC-anti-Foxp3, and PE-anti-IFN- $\gamma$ mAbs or appropriate fluorochrome-conjugated control $\mathrm{Abs}$, and then cells were analyzed by flow cytometry. Electric gates were placed on $\mathrm{CD} 45^{+} \mathrm{CD} 3^{+}$lymphocytes $(\mathrm{T}$ cells $), \mathrm{CD} 45^{+} \mathrm{CD} 3{ }^{+} \mathrm{CD} 8^{+}$ $\left(\mathrm{CD}^{+} \mathrm{T}\right.$ cells), or $\mathrm{CD} 45^{+} \mathrm{CD} 3^{+} \mathrm{CD} 4^{+} \mathrm{Foxp}^{-}$(Tcon), and the percentages of $\mathrm{CD} 8^{+}$, Foxp3 $3^{-} \mathrm{CD} 4^{+}$(Tcon), and Foxp3 ${ }^{+} \mathrm{CD} 4^{+}$(Treg) within T-cell gate and IFN- $\gamma^{+}$cells within $\mathrm{CD} 8^{+} \mathrm{T}$ cells or Tcon were analyzed. Data shown are the combined results from two independent experiments with each group of five mice. The bars show the mean values \pm SD. *Statistically different $(p<0.05)$. 
responses by modulating Tregs and $\mathrm{CD}^{+} \mathrm{T}$ cells, we examined much earlier time points after resiquimod injection, focusing on DC function. We showed that serum IFN- $\alpha$ was transiently upregulated at $3 \mathrm{hr}$ after resiquimod injection (Table 1); thus, DCs, especially pDCs, might have been targeted by resiquimod, as pDCs express high levels of TLR7 [28]. We examined the expression of IL-12, MHC class II, and CD86 in PDCA- $1^{+}$pDCs and PDCA$1^{-}$conventional DCs (cDCs) in regional lymph nodes (RLNs). As expected, resiquimod application induced IL-12 expression by pDCs at $3 \mathrm{hr}$. IL-12 expression then declined at $12 \mathrm{hr}$ (Figure 4A and 4C), with kinetical change similar to that of IFN- $\alpha$ as shown in Table 1. Cell surface MHC class II and CD86 expression, which are critical for antigenpresenting capacity, were also increased on pDCs, with peak expression at $12 \mathrm{hr}$ (Figure 4B and 4C). In the case of cDCs, transient upregulation of IL-12 was a little delayed (at $12 \mathrm{hr}$ ), and there was a simultaneous upregulation in MHC class II and CD86 expression. In particular, MHC class $\mathrm{II}^{\text {high }} \mathrm{CD} 86^{\text {high }}$ fraction in $\mathrm{cDCs}$ was dramatically increased after $12 \mathrm{hr}$ (Figure 4B, right panels). The upregulated expression of MHC class II and CD86 were maintained until $24 \mathrm{hr}$. To examine whether $\mathrm{cDC}$ activation by resiquimod is dependent on pDC, we compared IL-12 expression by cDCs in vitro using whole and pDC-depleted splenocytes. Even after depletion of pDCs, resiquimod stimulation induced a comparable level of IL-12 expression (Supplementary Figure 1), suggesting that resiquimod can directly activate $\mathrm{cDCs}$ without $\mathrm{pDC}$-mediated help. These results indicate that systemic resiquimod administration augmented the activation of both pDCs and cDCs in the circulation and RLNs.

\section{Resiquimod enhances activation of $\mathrm{CD8}^{+} \mathrm{T}$ cells in RLNs and the TME}

Because activation of DCs at an earlier time point might amplify the priming of $\mathrm{T}$ cells in RLNs, we next examined the activation status of $\mathrm{T}$ cells by evaluating IFN- $\gamma$ (a critical effector cytokine) and Ki-67 (a proliferation marker) at day 12. Resiquimod administration did not affect the percentage of $\mathrm{CD}^{+} \mathrm{T}$ cells, but it significantly increased the proportion of three activated states (IFN- $\gamma^{+} \mathrm{Ki}-67^{-}$, IFN- $\gamma^{+} \mathrm{Ki}-67^{+}$, and IFN- $\gamma^{-} \mathrm{Ki}-67^{+}$) of $\mathrm{CD}^{+} \mathrm{T}$ cells and reciprocally decreased the proportion of non-activated IFN- $\gamma^{-} \mathrm{Ki}-67^{-} \mathrm{CD}^{+} \mathrm{T}$ cells (Figure $5 \mathrm{~A}$ ). In contrast to that of $\mathrm{CD} 8^{+} \mathrm{T}$ cells, activation of $\mathrm{CD}^{+} \mathrm{T}$ cells, as assessed by the $\mathrm{CD} 8{ }^{-} \mathrm{CD} 3^{+}$fraction, was minimal. Consistent with the findings for $\mathrm{RLN} \mathrm{CD}^{+} \mathrm{T}$ cells, TIL $\mathrm{CD}^{+} \mathrm{T}$ cells, but not TIL CD4 ${ }^{+} \mathrm{T}$ cells, also showed a greater proportion of the IFN- $\gamma^{+} \mathrm{Ki}-67^{+}$fraction at this time point (Figure 5B). These results suggest that resiquimod administration efficiently enhanced the priming of $\mathrm{CD}^{+}$ $\mathrm{T}$ cells through modification of the antigen-presenting capacity of DCs.

\section{A limited dose of resiquimod exerts combinational effects with PD-L1 blockade therapy}

Our results suggest that resiquimod may be used as a companion drug for PD-1/PD-L1 blockade therapy. We titrated the concentration of resiquimod $(0.4,0.8$, and 1.7 $\mu \mathrm{g} /$ mouse) and examined the tumor volume of SCCVII. The inhibitory effects of resiquimod monotherapy were dose-dependent, and doses of 0.8 and $0.4 \mu \mathrm{g}$ showed marginal effects (Figure 6A). Additionally, we examined the effects of limited doses (1.0 and $0.5 \mu \mathrm{g} / \mathrm{mouse}$ ) of resiquimod in addition to the PD-L1 blockade. Although these doses were not effective in monotherapy, additional resiquimod treatment along with the PD-L1 blockade further decreased the tumor volume (Figure 6B). We next examined whether the decreased frequency of anti-PD-L1 therapy was still effective when it was combined with resiquimod. We decreased the frequency of anti-PD-L1 treatment to the half (from twice per week to once per week). The decreased frequency of anti-PD-L1 therapy under the resiquimod treatment consistently showed comparable effects (Figure 6C). These results suggest that limited doses of systemic resiquimod administration enable to overcome resistance to PD-L1 blockade, and allow for the decreased usage of the anti-PD-L1 antibody.

\section{DISCUSSION}

We demonstrated the differential effects of systemic low-dose resiquimod administration in monotherapy and in combined treatment with PD-L1 blockade in two PDL1 blockade-resistant tumor models that exhibit different profiles of TILs. Resiquimod monotherapy resulted in some tumor reduction in Colon 26, and showed a relatively higher recruitment and activation of $\mathrm{CD}^{+} \mathrm{T}$ cells in the TME. Combined treatment did not clearly affect outside tumor size, but it did augment the necrotic lesions of inside tumors that were correlated with a marked reduction of Tregs in the TME. Unlike Colon 26 tumors, resiquimod monotherapy in SCCVII tumors with impaired $\mathrm{CD}^{+} \mathrm{T}$ cell activation and accelerated Treg recruitment in the TME markedly decreased tumor size along with $\mathrm{CD} 8^{+} \mathrm{T}$ cell accumulation and a reduction of Tregs. Combined resiquimod treatment with PD-L1 blockade exerted additional effects on tumor size and Treg and $\mathrm{CD}^{+} \mathrm{T}$ cell recruitment.

Our results indicate that the efficacy of systemic resiquimod administration is highly superior in Tregdominant tumors, such as SCCVII. This suggests that low-dose resiquimod administration converts resistance to PD-L1 blockade therapy that is caused by Treg accumulation. We previously reported that Treg depletion in a SCCVII model resulted in almost complete eradication of tumors [29]; thus, Tregs are critical immune regulators that accelerate SCCVII tumor growth. Even in Colon 26, 
combined treatment decreased Treg accumulation, resulting in expansion of the necrotic area. In both tumor models, resiquimod treatment was efficacious because it resulted in Treg attenuation in the TME. Previous reports using a relatively high dose of TLR7/8 agonists (resiquimod and loxoribin) also demonstrated de novo inhibition of Tregs via modulation of DCs and involvement of IL-6 [30, 31]. Resiquimod-treated DCs have been shown to downregulate Foxp3 expression and suppress the function of Tregs [30]. We also observed that generation of induced Tregs was
A
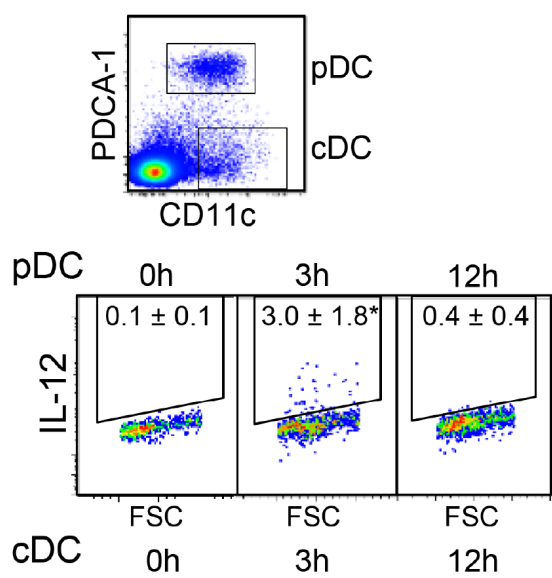

CDC Oh $\quad 3 \mathrm{~h} \quad 12 \mathrm{~h}$

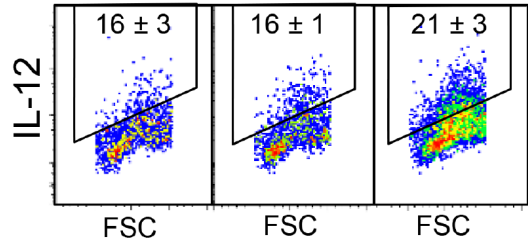

C $(\%)$

FSC

FSC

IL-12

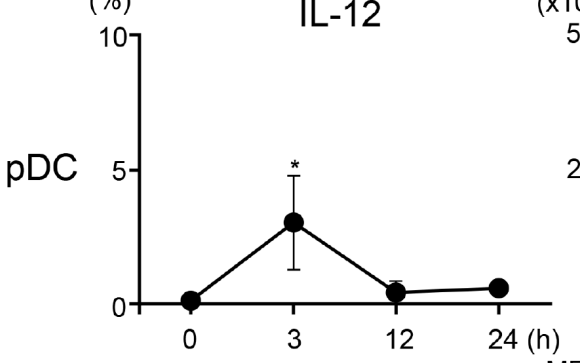

IL-12

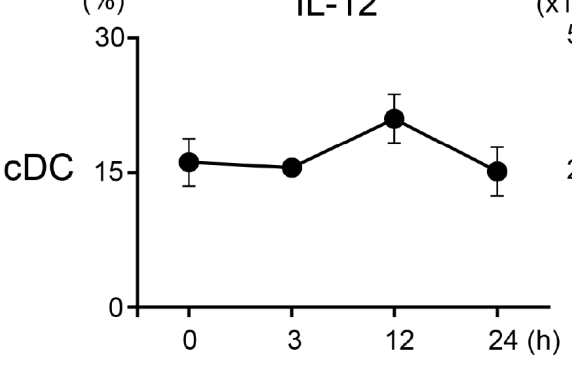

B $\mathrm{pDC} \quad \mathrm{MHC} I \mathrm{CD} 86$
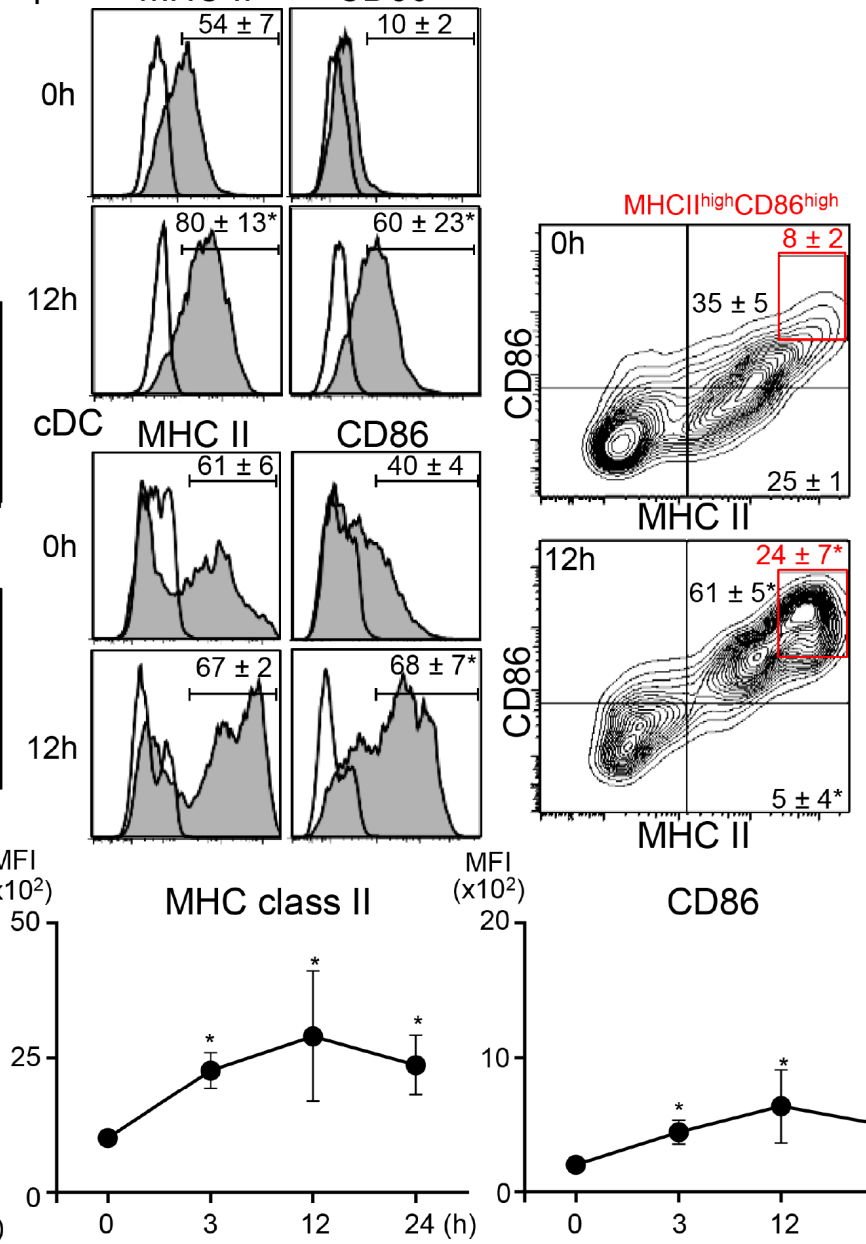

${ }^{20}{ }^{20}$

CD86
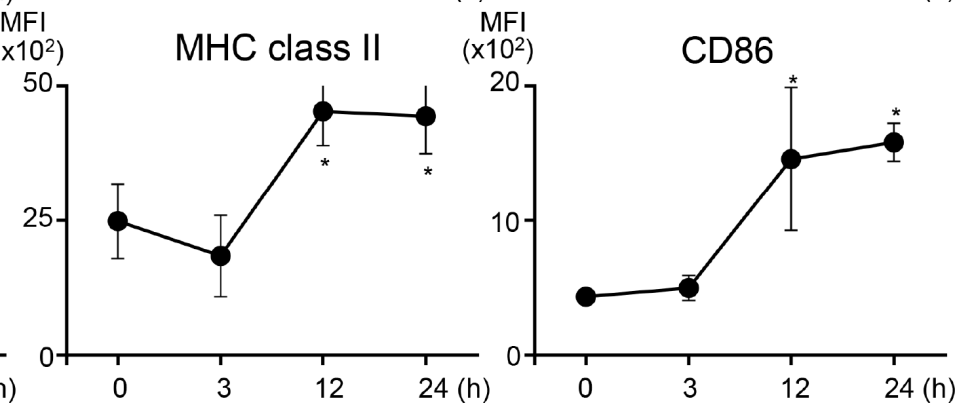

Figure 4: Systemic administration of low-dose resiquimod induces activation of both types of DCs. RLN cells from irradiated SCCVII tumor-injected mice at the indicated time points were isolated. Resiquimod was i.p. injected at the time of tumor injection. Cells were stained with PerCP-Cy5.5-anti-CD11c, APC-anti-PDCA-1, FITC-anti-MHC class II, and either PE-anti-CD86 or PE-anti-IL-12 mAbs or appropriate fluorochrome-conjugated control Abs. Stained cells were analyzed by flow cytometry. An electronic gate was placed on PDCA $-1^{+} \mathrm{CD} 11 \mathrm{c}^{+}$for $\mathrm{pDCs}$ or PDCA-1-CD11 $\mathrm{c}^{+}$for $\mathrm{cDCs}$, as shown in the upper panel of A, and the expression levels of IL-12, MHC class II, and CD86 were analyzed. Expression levels of IL-12 (A) and MHC class II and CD86 (B) at the indicated time points are presented as dotted plots, histograms, or contour plots. The values shown are the mean percentages \pm SD in each DC fraction. The red boxes in (B) show MHC class II $^{\text {high }} \mathrm{CD} 86^{\text {high }}$ fractions and their mean values are shown in red. (C) Kinetic changes in the percentage of IL- $12^{+}$cells and the mean fluorescence intensity (MFI) of MHC class II and CD86 expression in each DC fraction are shown. All values shown are the mean \pm SD from three mice. Representative data are shown. Statistically different from the values at $0 \mathrm{hr}(p<0.05)$. 
clearly inhibited by the resiquimod-treated DCs in coculture experiments with $\mathrm{RAG}^{-/-} \mathrm{DO} 11.10 \mathrm{CD}^{+} \mathrm{T}$ cells and OVA-pulsed DCs (Supplementary Figure 2). IL-6 production in the pre-DC culture in the presence of OVA and a maturation-cytokine, TNF- $\alpha$ increased almost tenfold by resiquimod stimulation (the mean $\pm \mathrm{SD}$; without resiquimod, $74.7 \pm 42.3 \mathrm{pg} / \mathrm{ml}$ and with resiquimod, 650.6 $\pm 44.5 \mathrm{pg} / \mathrm{ml}$ ). This suggests that resiquimod-treated DCs inhibit Treg generation and IL-6 secreted from resiquimodactivated DCs might be a candidate cytokine involved in Treg inhibition.

In this study, we observed that systemic administration of low-dose resiquimod induced a transient (3 hr) upregulation of IFN- $\alpha$ in sera and IL-12, MHC class II, and CD86 expression by pDCs in the RLNs. Thus, pDCs in the circulation, including tumor sites and

A
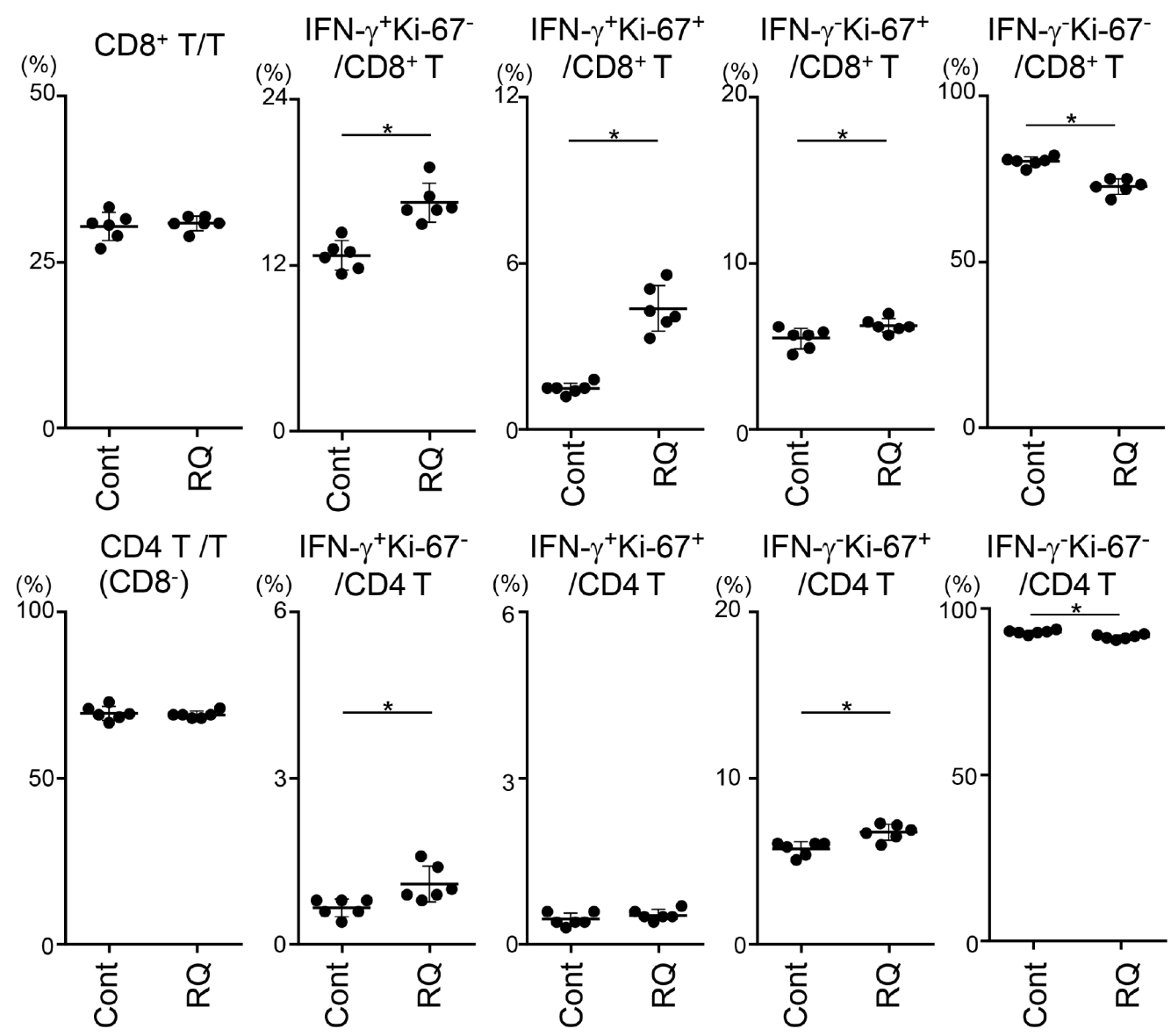

IFN- $\gamma^{+} \mathrm{Ki}-67^{+}$

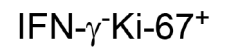

\section{IFN- $\gamma^{-} \mathrm{Ki}-67^{-}$}
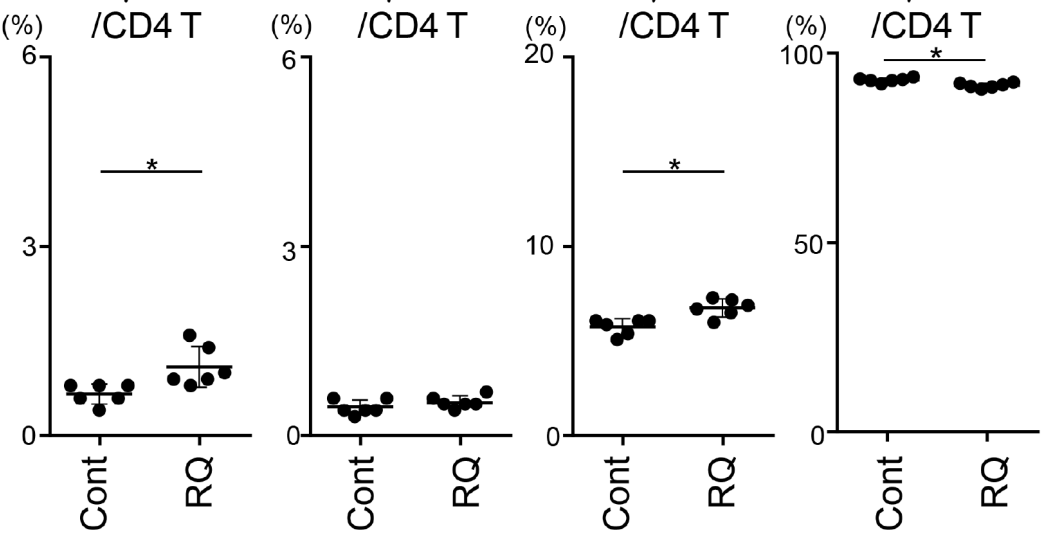

B

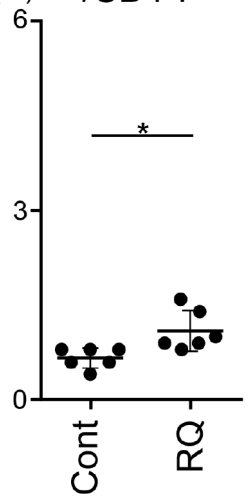

$\mathrm{CD}^{+} \mathrm{T}$

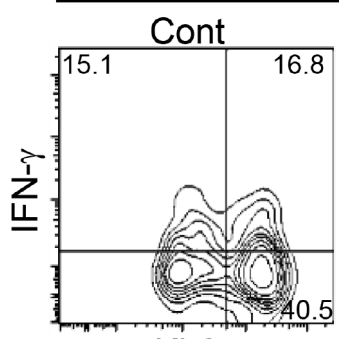

Ki-67

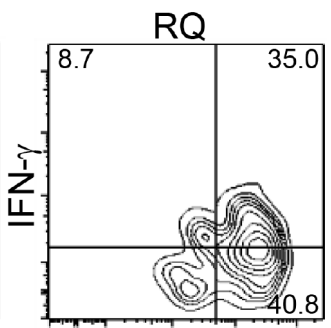

Ki-67

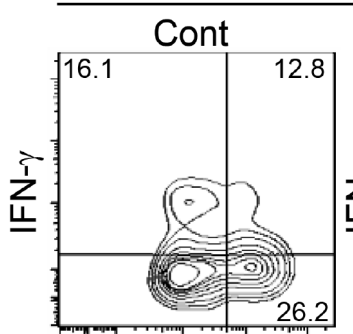

Ki-67

CD4 T

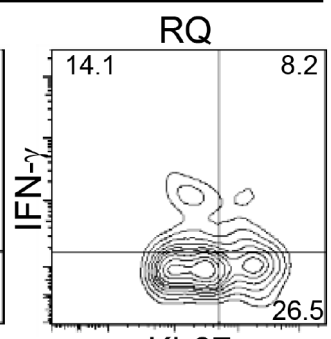

Ki-67

Figure 5: Resiquimod enhances activation of $\mathbf{C D 8}^{+} \mathbf{T}$ cells in RLNs and the TME. RLNs (A) and tumor masses (B) from SCCVII-inoculated mice treated with control reagents or resiquimod at days 0, 3, 7, and 10 were obtained at 12 days. Tumor masses from five to six mice were combined, and TIL fractions were isolated. RLN cells and TILs were stimulated and stained with Brilliant Violet 510-anti-CD45, APC-eFluor780-anti-CD3, PerCP-Cy5.5-anti-CD8, APC-anti-IFN- $\gamma$, FITC-anti-Ki-67 mAbs or appropriate fluorochromeconjugated control Abs. Stained cells were analyzed by flow cytometry. (A) Electric gates were placed on $\mathrm{CD}^{+}, \mathrm{CD}^{+} \mathrm{CD}^{+}$, or $\mathrm{CD} 3{ }^{+} \mathrm{CD} 8{ }^{-}$ (as $\mathrm{CD} 4^{+} \mathrm{T}$ ) lymphocytes, and then the percentages of the indicated fractions were analyzed. Data shown are representative from two independent experiments with similar results. The bars show the mean values \pm SD from each group of six mice. *Statistically different $(p$ $<0.05$ ). (B) An electronic gate was placed on $\mathrm{CD}_{4} 5^{+} \mathrm{CD} 3^{+} \mathrm{CD}^{+}$or $\mathrm{CD} 45^{+} \mathrm{CD} 3^{+} \mathrm{CD} 8$ (as $\left.\mathrm{CD} 4^{+} \mathrm{T}\right)$ lymphocytes, and the expression levels of Ki-67 and IFN- $\gamma$ are shown as contour plots. Data are representative from two independent experiments with similar results. 
secondary lymphoid organs, are the initial responsive target cells for resiquimod. We also observed that resiquimod stimulation in vitro efficiently increased $\mathrm{CD} 8^{+} \mathrm{PDCA}-1^{+}$ DCs and pre-depletion of $\mathrm{pDC}$ failed to increase $\mathrm{CD}^{+} \mathrm{DCs}$ (Supplementary Figure 3). It has been shown that unlike regular splenic pDCs, TLR ligand-activated pDCs play a critical role in the cross-priming of tumoral-antigens to generate effector CTLs in RLNs [32]. Although we have not directly examined function of resiquimod-treated pDCs, it is possible that resiquimod-stimulated $\mathrm{CD} 8^{+}$ pDCs may contribute to cross-priming. However, pDCs licensed by TLR ligands alone fail to induce efficient CTLs and cooperate with other RLN cDCs or a subset of $\mathrm{XCR} 1^{+} \mathrm{DCs}$ to promote $\mathrm{T}-\mathrm{cell}$ recruitment and activation [33-35]. Thus, it is likely that activation of pDCs and cDCs by systemic resiquimod injection and cooperation by both types of licensed DCs amplify T- cell priming against tumor antigens, resulting in efficient induction of CTLs and attenuation of Treg generation. This may explain why lowdose resiquimod efficiently affects the numbers of $\mathrm{CD}^{+} \mathrm{T}$, Tregs, and the CD8/Treg ratio.

We cannot presently rule out the involvement of TAMs or MDSCs in resiquimod action. TILs from SCCVII tumor-bearing mice contained a greater proportion of $\mathrm{CD}_{11 \mathrm{~b}^{+}}$TAMs, which was decreased by resiquimod monotherapy (Supplementary Figure 4B). Recent reports demonstrated that intratumoral injection of a phospholipidconjugated TLR7 agonist increased the ratio of M1/M2 TAMs in several tumor models [24], and subcutaneous injection of resiquimod in CT26 tumors converted monocytic MDSCs into non-suppressive state [23]. Further studies are required to clarify their involvement.

Nevertheless, our results indicate that systemic administration of low-dose resiquimod as a companion drug with PD-1/PD-L1 blockade therapy offers considerable benefits. Although the effects of intratumoral injection of a TLR7/8 agonist (3M-052/ MEDI9197) alone and in combination with anti-PD-L1 antibody (durvalumab) against solid tumors are being studied in a clinical trial
(ClinicalTrials.gov \#NCT02556463), intratumoral injection requires the selection of eligible cases and the use of special techniques by medical professionals. Systemic administration is much more convenient and broadly applicable. Once a suitable dose that does not cause adverse effects, as represented by acute proinflammatory cytokine secretion, is determined for clinical use, systemic administration of low-dose resiquimod combined with PD-1/PD-L1 blockade therapy, especially in immunosuppressive tumors, such as $\mathrm{HNC}$, may have a great potential to eradicate tumors. Our results suggest that systemic administration of low-dose resiquimod is useful as a companion drug with PD-1/PD-L1 blockade therapy.

\section{MATERIALS AND METHODS}

\section{Mice}

Female 6-7-week-old BALB/c and C3H mice were purchased from Japan SLC (Hamamatsu, Japan). All mice were maintained under specific pathogen-free conditions at Tokyo Medical and Dental University. All experimental procedures were reviewed and approved by the Animal Care and Use Committee of Tokyo Medical and Dental University (0170344A).

\section{Tumor cell lines and treatment}

Two tumor cell lines, SCCVII (a spontaneously arising squamous cell carcinoma cell line derived from C3H mice, $2 \times 10^{5}$ cells) $[10,25,26,29]$ and Colon 26 (a carcinogen-induced undifferentiated colon carcinoma cell line originated from BALB/c mice, $5 \times 10^{5}$ cells) $[29,36,37]$ were used. For induction of PD-L1 in vitro, cells were cultured in the presence or absence of IFN- $\gamma(10 \mathrm{ng} / \mathrm{ml}$, BD Biosciences, San Diego, CA) for $72 \mathrm{hr}$. Cultured tumor cells were freeze-stocked at the same time, and cells that had been cultured for 5-7 days were used for tumor inoculation. Tumor cells were injected subcutaneously (s.c.) into the
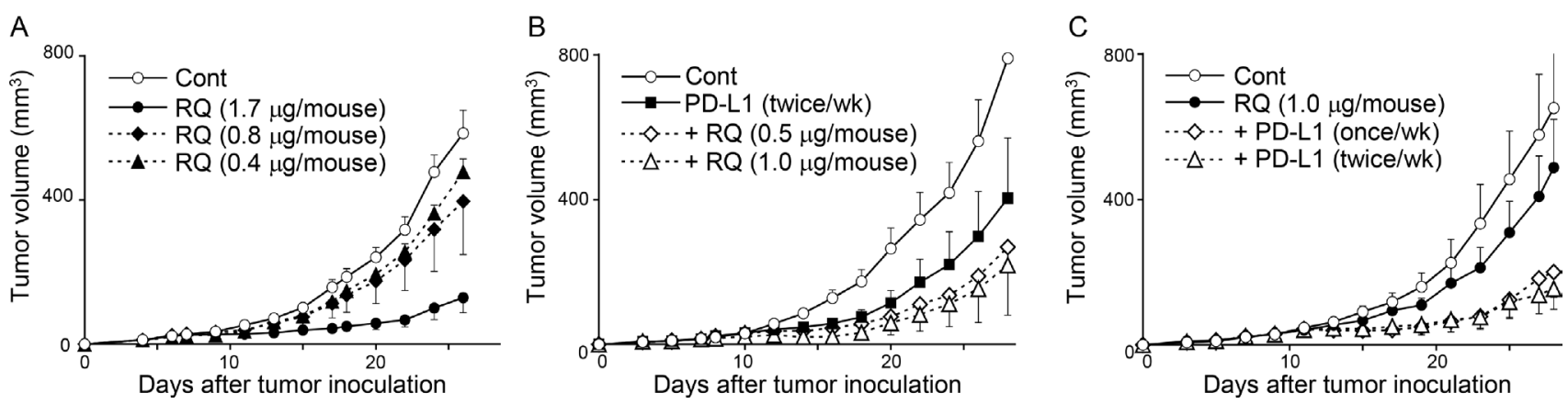

Figure 6: A limited dose of resiquimod exerts combinational effects with PD-L1 blockade therapy. C3H mice received s.c. injection of SCCVII tumor cells, and tumor growth was measured as described in Figure 2. The indicated doses of resiquimod (RQ) and anti-PD-L1 mAb (200 $\mu \mathrm{g}$ /mouse) were injected i.p. twice per week unless otherwise noted. All treatments were started at 7 day after tumor inoculation. The values are the mean \pm SEM from each group of five mice. Data shown are representative from two independent experiments with similar results. 
shaved right flank of syngeneic mice, and tumor size was measured as described previously [10, 29]. Resiquimod was synthesized with $\geq 98 \%$ purity by a contract research organization and provided in lyophilized form. Comparable activity with R848 purchased from InvivoGen (San Diego, CA) was validated by IFN- $\alpha$, IL-12 and TNF- $\alpha$ secretion using mouse and human pan-DC fractions by ELISA. In most experiments, unless otherwise noted, treatment with either resiquimod $(1.7 \mu \mathrm{g} /$ mouse $)$ or anti-PD-L1 mAb (MIH5, rat IgG2a, $200 \mu \mathrm{g} / \mathrm{mouse}$ ) [38], or with both was started at day 0 for Colon 26 and day 7 for SCCVII by intraperitoneal (i.p.) injection twice per week until day 17.

\section{Isolation of TILs and LN cells}

To isolate TILs, resected tumor masses were minced and digested with collagenase I, hyaluronidase, and DNase as described previously [39]. Then alive cells were separated using a lymphocyte separation medium. RLNs were collected from the tumor-inoculated side of inguinal and axillary LNs. For analysis of DCs, RLN cells were isolated using type I collagenase as described previously [40].

\section{Monoclonal antibodies and flow cytometry}

Monoclonal antibodies (mAbs) against CD3 (17A2, rat $\operatorname{IgG} 2 b), \mathrm{CD} 4$ (GK1.5, rat $\mathrm{IgG} 2 \mathrm{~b}), \mathrm{CD} 8$ (53-6.72, rat IgG1), CD45 (30-F11, rat IgG2b), IFN- $\gamma$ (XMG1.2, rat IgG1), Foxp3 (FJK-165, rat IgG2a), CD11b (M1/70, rat IgG2b), CD11c (N418, Armenian hamster IgG), PDCA1 (eBio927, rat IgG2b), CD86 (PO3.1, rat IgG2b), MHC class II (M5/114, rat IgG2b), PD-L1 (MIH5, rat IgG2a), IL-12/IL-23 p40 (C17.8, rat IgG2a), and Ki-67 (Sola15, rat IgG2a) were used. All FITC-, PE-, APC-, PerCP-Cy5.5-, PE-Cy7-, APC-eFluor780-, V450-, and Brilliant Violet 510-conjugated $\mathrm{mAbs}$ were obtained from eBioscience (San Diego, CA), BD-Biosciences or Biolegend (San Diego, CA). Non-specific binding via Fc $\gamma \mathrm{R}$ and multicolor cell staining for cell surface and intracellular molecules was performed as described previously [10]. Stained cells were analyzed using FACSCalibur or FACSVerse (BD Biosciences) with Cell Quest Pro or FACSuite software. All data were analyzed using FlowJo software (Tree Star, Ashland, OR).

\section{Assessment of serum proinflammatory cytokines and activation status of DCs after resiquimod injection}

Cultured SCCVII cells were 40-Gy irradiated to stop cell growth. Intact or irradiated-SCCVII tumor- $\left(1 \times 10^{6}\right.$ cells/site) inoculated mice received i.p. administration of resiquimod ( $1.7 \mu \mathrm{g} /$ mouse); then, blood and RLNs (inguinal and axillary LNs) were collected at the indicated time points. Serum cytokines (IFN- $\alpha$, IL- $1 \beta$, IL- 6 , and TNF- $\alpha$ ) were measured using ELISA kits according to the manufacture's protocol (eBioscience). For measurement of intracellular IL12 , cells were cultured in the presence of brefeldin A for $3 \mathrm{hr}$.

\section{Immunohistochemistry}

Cryostat sections $(6 \mu \mathrm{m})$ of tumor tissue were stained with anti- PD-L1 (MIH6, rat IgG2a), and enzymatic immunohistochemistry was performed as described previously [38].

\section{Statistical analysis}

Statistical analyses were performed using the MannWhitney $U$-test or the Mann-Whitney $U$-test with Bonferroni correction. Statistical significance was set at $p<0.05$.

\section{Abbreviations}

APC, antigen-presenting cell; cDC, conventional dendritic cell; CD8/Treg, effector $\mathrm{CD}^{+} \mathrm{T}$ cells/Tregs; CTL, cytotoxic T lymphocyte; DC, dendritic cells; HNC, head and neck cancer; MDSC, myeloid-derived suppressor cell; pDC, plasmacytoid dendritic cell; RLN, regional lymph node; SCC, squamous cell carcinoma; TAM, tumorassociated macrophage; Tcon, conventional CD4 ${ }^{+} \mathrm{T}$ cell; TIL, tumor-infiltrating lymphocyte; TLR, Toll-like receptor; TME, tumor microenvironment; Treg, regulatory $\mathrm{T}$ cell

\section{Author contributions}

N.N. and M.A. contributed to conception and design of the research, performed the experiments, data acquisition, analysis, interpretation and wrote the paper. H.T., Y.K., Y.X. and Y.K. contributed to perform the experiments. T.O. and S.N. contributed to technical assistant for the research and data analysis. L.L., W.L. and H.H. contributed to conception and critical discussion of the research and manuscript preparation.

\section{CONFLICTS OF INTEREST}

The authors declare no competing financial interests.

\section{FUNDING}

This work was supported by grants from Japan Society for the Promotion of Science (JSPS) Grants-inAid for Scientific Research (KAKENHI) (A26253086, A23249082 to M.A.).

\section{REFERENCES}

1. Korman AJ, Peggs KS, Allison JP. Checkpoint blockade in cancer immunotherapy. Adv Immunol. 2006; 90:297-339. 
2. Stewart TJ, Smyth MJ. Improving cancer immunotherapy by targeting tumor-induced immune suppression. Cancer Metastasis Rev. 2011; 30:125-40.

3. Pardoll DM. The blockade of immune checkpoints in cancer immunotherapy. Nat Rev Cancer. 2012; 12:252-64.

4. Zou W, Wolchok JD, Chen L. PD-L1 (B7-H1) and PD-1 pathway blockade for cancer therapy: Mechanisms, response biomarkers, and combinations. Sci Transl Med. 2016; 8:328rv4.

5. Schumacher TN, Schreiber RD. Neoantigens in cancer immunotherapy. Science. 2015; 348:69-74.

6. McGranahan N, Furness AJ, Rosenthal R, Ramskov S, Lyngaa R, Saini SK, Jamal-Hanjani M, Wilson GA, Birkbak NJ, Hiley CT, Watkins TB, Shafi S, Murugaesu N, et al. Clonal neoantigens elicit $\mathrm{T}$ cell immunoreactivity and sensitivity to immune checkpoint blockade. Science. 2016; 351:1463-9.

7. Vasquez-Dunddel D, Pan F, Zeng Q, Gorbounov M, Albesiano E, Fu J, Blosser RL, Tam AJ, Bruno T, Zhang H, Pardoll D, Kim Y. STAT3 regulates arginase-I in myeloidderived suppressor cells from cancer patients. J Clin Invest. 2013; 123:1580-9.

8. Sun W, Li WJ, Wei FQ, Wong TS, Lei WB, Zhu XL, Li J, Wen WP. Blockade of MCP-1/CCR4 signaling-induced recruitment of activated regulatory cells evokes an antitumor immune response in head and neck squamous cell carcinoma. Oncotarget. 2016; 7:37714-27. https://doi. org/10.18632/oncotarget.9265.

9. Davis RJ, Van Waes C, Allen CT. Overcoming barriers to effective immunotherapy: MDSCs, TAMs, and Tregs as mediators of the immunosuppressive microenvironment in head and neck cancer. Oral Oncol. 2016; 58:59-70.

10. Kondo Y, Ohno T, Nishii N, Harada K, Yagita H, Azuma M. Differential contribution of three immune checkpoint (VISTA, CTLA-4, PD-1) pathways to antitumor responses against squamous cell carcinoma. Oral Oncol. 2016; 57:54-60.

11. Twyman-Saint Victor C, Rech AJ, Maity A, Rengan R, Pauken KE, Stelekati E, Benci JL, Xu B, Dada H, Odorizzi PM, Herati RS, Mansfield KD, Patsch D, et al. Radiation and dual checkpoint blockade activate non-redundant immune mechanisms in cancer. Nature. 2015; 520:373-7.

12. Vasilakos JP, Tomai MA. The use of Toll-like receptor $7 / 8$ agonists as vaccine adjuvants. Expert Rev Vaccines. 2013; 12:809-19.

13. Aranda F, Vacchelli E, Obrist F, Eggermont A, Galon J, Sautes-Fridman C, Cremer I, Henrik Ter Meulen J, Zitvogel L, Kroemer G, Galluzzi L. Trial Watch: Tolllike receptor agonists in oncological indications. Oncoimmunology. 2014; 3:e29179.

14. Dowling JK, Mansell A. Toll-like receptors: the swiss army knife of immunity and vaccine development. Clin Transl Immunology. 2016; 5:e85.
15. Dockrell DH, Kinghorn GR. Imiquimod and resiquimod as novel immunomodulators. J Antimicrob Chemother. 2001; 48:751-5.

16. Schon MP, Schon M. TLR7 and TLR8 as targets in cancer therapy. Oncogene. 2008; 27:190-9.

17. Smits EL, Ponsaerts P, Berneman ZN, Van Tendeloo VF. The use of TLR7 and TLR8 ligands for the enhancement of cancer immunotherapy. Oncologist. 2008; 13:859-75.

18. Meyer T, Surber C, French LE, Stockfleth E. Resiquimod, a topical drug for viral skin lesions and skin cancer. Expert Opin Investig Drugs. 2013; 22:149-59.

19. Hayashi T, Gray CS, Chan M, Tawatao RI, Ronacher L, McGargill MA, Datta SK, Carson DA, Corr M. Prevention of autoimmune disease by induction of tolerance to Toll-like receptor 7. Proc Natl Acad Sci U S A. 2009; 106:2764-9.

20. Micali G, Lacarrubba F, Nasca MR, Schwartz RA. Topical pharmacotherapy for skin cancer: part I. Pharmacology. J Am Acad Dermatol. 2014; 70:965.e1-12; quiz 77-8.

21. Mark KE, Spruance S, Kinghorn GR, Sacks SL, Slade HB, Meng TC, Selke S, Magaret A, Wald A. Three phase III randomized controlled trials of topical resiquimod 0.01-percent gel to reduce anogenital herpes recurrences. Antimicrob Agents Chemother. 2014; 58:5016-23.

22. Rook AH, Gelfand JM, Wysocka M, Troxel AB, Benoit B, Surber C, Elenitsas R, Buchanan MA, Leahy DS, Watanabe R, Kirsch IR, Kim EJ, Clark RA. Topical resiquimod can induce disease regression and enhance T-cell effector functions in cutaneous T-cell lymphoma. Blood. 2015; 126:1452-61.

23. Spinetti T, Spagnuolo L, Mottas I, Secondini C, Treinies M, Ruegg C, Hotz C, Bourquin C. TLR7-based cancer immunotherapy decreases intratumoral myeloid-derived suppressor cells and blocks their immunosuppressive function. Oncoimmunology. 2016; 5:e1230578.

24. Sato-Kaneko F, Yao S, Ahmadi A, Zhang SS, Hosoya T, Kaneda MM, Varner JA, Pu M, Messer KS, Guiducci C, Coffman RL, Kitaura K, Matsutani T, et al. Combination immunotherapy with TLR agonists and checkpoint inhibitors suppresses head and neck cancer. JCI Insight. 2017; 2:e93397

25. O'Malley BW, Cope KA, Chen SH, Li D, Schwarta MR, Woo SL. Combination gene therapy for oral cancer in a murine model. Cancer Res. 1996; 56:1737-41.

26. Khurana D, Martin EA, Kasperbauer JL, O’Malley BW Jr, Salomao DR, Chen L, Strome SE. Characterization of a spontaneously arising murine squamous cell carcinoma (SCC VII) as a prerequisite for head and neck cancer immunotherapy. Head Neck. 2001; 23:899-906.

27. Chatterjee S, Crozet L, Damotte D, Iribarren K, Schramm C, Alifano M, Lupo A, Cherfils-Vicini J, Goc J, Katsahian S, Younes M, Dieu-Nosjean MC, Fridman WH, et al. TLR7 promotes tumor progression, chemotherapy resistance, and poor clinical outcomes in non-small cell lung cancer. Cancer Res. 2014; 74:5008-18. 
28. Edwards AD, Diebold SS, Slack EM, Tomizawa H, Hemmi H, Kaisho T, Akira S, Reis e Sousa C. Toll-like receptor expression in murine DC subsets: lack of TLR7 expression by $\mathrm{CD} 8 \alpha^{+} \mathrm{DC}$ correlates with unresponsiveness to imidazoquinolines. Eur J Immunol. 2003; 33:827-33.

29. Piao J, Kamimura Y, Iwai H, Cao Y, Kikuchi K, Hashiguchi M, Masunaga T, Jiang H, Tamura K, Sakaguchi S, Azuma M. Enhancement of T-cell-mediated anti-tumour immunity via the ectopically expressed glucocorticoid-induced tumour necrosis factor receptor-related receptor ligand (GITRL) on tumours. Immunology. 2009; 127:489-99.

30. Hackl D, Loschko J, Sparwasser T, Reindl W, Krug AB. Activation of dendritic cells via TLR7 reduces Foxp3 expression and suppressive function in induced Tregs. Eur J Immunol. 2011; 41:1334-43.

31. Wang C, Zhou Q, Wang X, Wu X, Chen X, Li J, Zhu Z, Liu B, Su L. The TLR7 agonist induces tumor regression both by promoting $\mathrm{CD} 4^{+} \mathrm{T}$ cells proliferation and by reversing $\mathrm{T}$ regulatory cell-mediated suppression via dendritic cells. Oncotarget. 2015; 6:1779-89. https://doi. org/10.18632/oncotarget.2757.

32. Mouries J, Moron G, Schlecht G, Escriou N, Dadaglio G, Leclerc C. Plasmacytoid dendritic cells efficiently crossprime naive $\mathrm{T}$ cells in vivo after TLR activation. Blood. 2008; 112:3713-22.

33. Yoneyama H, Matsuno K, Toda E, Nishiwaki T, Matsuo N, Nakano A, Narumi S, Lu B, Gerard C, Ishikawa S, Matsushima K. Plasmacytoid DCs help lymph node DCs to induce anti-HSV CTLs. J Exp Med. 2005; 202:425-35.

34. Budimir N, de Haan A, Meijerhof T, Waijer S, Boon L, Gostick E, Price DA, Wilschut J, Huckriede A. Critical role of TLR7 signaling in the priming of cross-protective cytotoxic T lymphocyte responses by a whole inactivated influenza virus vaccine. PLoS One. 2013; 8:e63163.

35. Brewitz A, Eickhoff S, Dahling S, Quast T, Bedoui S, Kroczek RA, Kurts C, Garbi N, Barchet W, Iannacone M, Klauschen F, Kolanus W, Kaisho T, et al. CD8 ${ }^{+}$T Cells Orchestrate pDC-XCR1 ${ }^{+}$Dendritic Cell Spatial and Functional Cooperativity to Optimize Priming. Immunity. 2017; 46:205-19.

36. Corbett TH, Griswold DP Jr, Roberts BJ, Peckham JC, Schabel FM Jr. Tumor induction relationships in development of transplantable cancers of the colon in mice for chemotherapy assays, with a note on carcinogen structure. Cancer Res. 1975; 35:2434-9.

37. Tanaka K, Matsui Y, Ishikawa S, Kawanishi T, Harada M. Oral ingestion of Lentinula edodes mycelia extract can restore the antitumor $\mathrm{T}$ cell response of mice inoculated with colon-26 cells into the subserosal space of the cecum. Oncol Rep. 2012; 27:325-32.

38. Tsushima F, Tanaka K, Otsuki N, Youngnak P, Iwai H, Omura K, Azuma M. Predominant expression of B7-H1 and its immunoregulatory roles in oral squamous cell carcinoma. Oral Oncol. 2006; 42:268-74.

39. Kobori H, Hashiguchi M, Piao J, Kato M, Ritprajak P, Azuma M. Enhancement of effector CD8+ T-cell function by tumour-associated $\mathrm{B} 7-\mathrm{H} 3$ and modulation of its counter-receptor triggering receptor expressed on myeloid cell-like transcript 2 at tumour sites. Immunology. 2010; 130:363-73.

40. Chalermsarp N, Azuma M. Identification of three distinct subsets of migrating dendritic cells from oral mucosa within the regional lymph nodes. Immunology. 2009; 127:558-66. 